\title{
Management of Female Urethral Diverticulum
}

\author{
Christian Goepel, Miklos Szakacs and Balint Farkas* \\ Vivantes Humboldt Clinic, Pelvic Floor and Incontinence Centre, Germany
}

Submission: June 01, 2018; Published: June 26, 2018

${ }^{*}$ Corresponding author: Balint Farkas, MD, Med Habil Vivantes Humboldt Clinic, Pelvic Floor and Incontinence Centre, Am Nordgraben 2, 13509, Berlin, Germany, Tel: +49-030-12-1873; Fax: +49-030-130-12-1874; Email: Balint.Farkas@vivantes.de

\begin{abstract}
Introduction: female urethral diverticulum is an uncommon pathologic condition, with symptoms ranging from pain, dyspareunia to variable urinary symptoms. Our aim was the summarize the diagnosis and the treatment options of urethral diverticulum.

Methods: a systematic review was carried out utilizing the publicly available medical databases, by using the keywords listed below.

Results: medical history and physical examination augmented by a physical examination and augmented by voiding cystourethrography, positive pressure urethrography, endovaginal sonography, or magnetic resonance imaging remains the cornerstone of the diagnosis. In symptomatic patients surgical solution is required, including endovaginal diverticulectomy, or marsupialization which are the best choice for treatment.
\end{abstract}

Conclusion: female UD has patients are usually candidates for operative treatment, although the currently available operative approaches have a relative high recurrence rate.

Keywords: Child Health Support Project; PASME; District of Dahra; knew family planning; Injectable methods; income-generating activity Abbreviations: UD: Urethral Diverticulum; SUI: Stress Urinary Incontinence (SUI); CT: Computer Tomography; MRI: Magnetic Resonance Imaging

\section{Introduction}

Urethral diverticulum (UD) is a rare and unique condition, defined as a pocket or pouch forms alongside the female urethra [1], with an overall annual incidence of $0.02 \%(17.9$ per 1.000.000) [2]. It is considered to be more common among African American women compared to Caucasians [3,4]. Two types of them are known, the congenital and the acquired form. While the congenital type is thought to be originate from the Gartner's duct, which is a vestigial remnant of the mesonephric duct (Wolffian duct) [5], the acquired forms could be iatrogenic, traumatic or inflammatory manifestations, leading to outflow obstruction of the paraurethral glands (Skene's gland) content [6]. The symptoms of the condition ranges from asymptomatic forms through the classic triad of postmicturition dribble, dyspareunia and dysuria, but might also include frequency, urgency, hematuria recurrent cystitis and urinary incontinence $[5,7]$. Our aim was to summarize the diagnosis and the therapy options of this rare condition.

\section{Results and Discussion}

\section{Diagnosis}

The diagnosis of UD is based on taking an extensive medical history focusing on the condition related specific symptoms. It is followed by a thorough physical examination, during which a palpable vaginal mass can be revealed, accompanied by coexisting stress urinary incontinence (SUI) in about $50 \%$ of the cases [2]. The diagnostic modalities include voiding cystourethrography, positive pressure urethrography, urethroscopy, endovaginal sonography, transrectal sonography, postvoid radiograph, computer tomography (CT) scan, and magnetic resonance imaging (MRI) [2]. Imaging techniques are crucial in the diagnosis making, among them MRI is the most commonly carried out examination. On the saggital T2-weighted images in patients with UD a low-signal density mass, with hemorrhage or inflammatory content, or cell debris can be seen. The cyst usually has peripheral rim enhancement and subtle irregularity 


\section{Journal of Gynecology and Women's Health}

suspicious to malignancy, and results the antrolateral dislocation

horseshoe-shaped diverticulum can be visualized (Figure 1).

of the urethra [8]. With endovaginal sonography lateral or

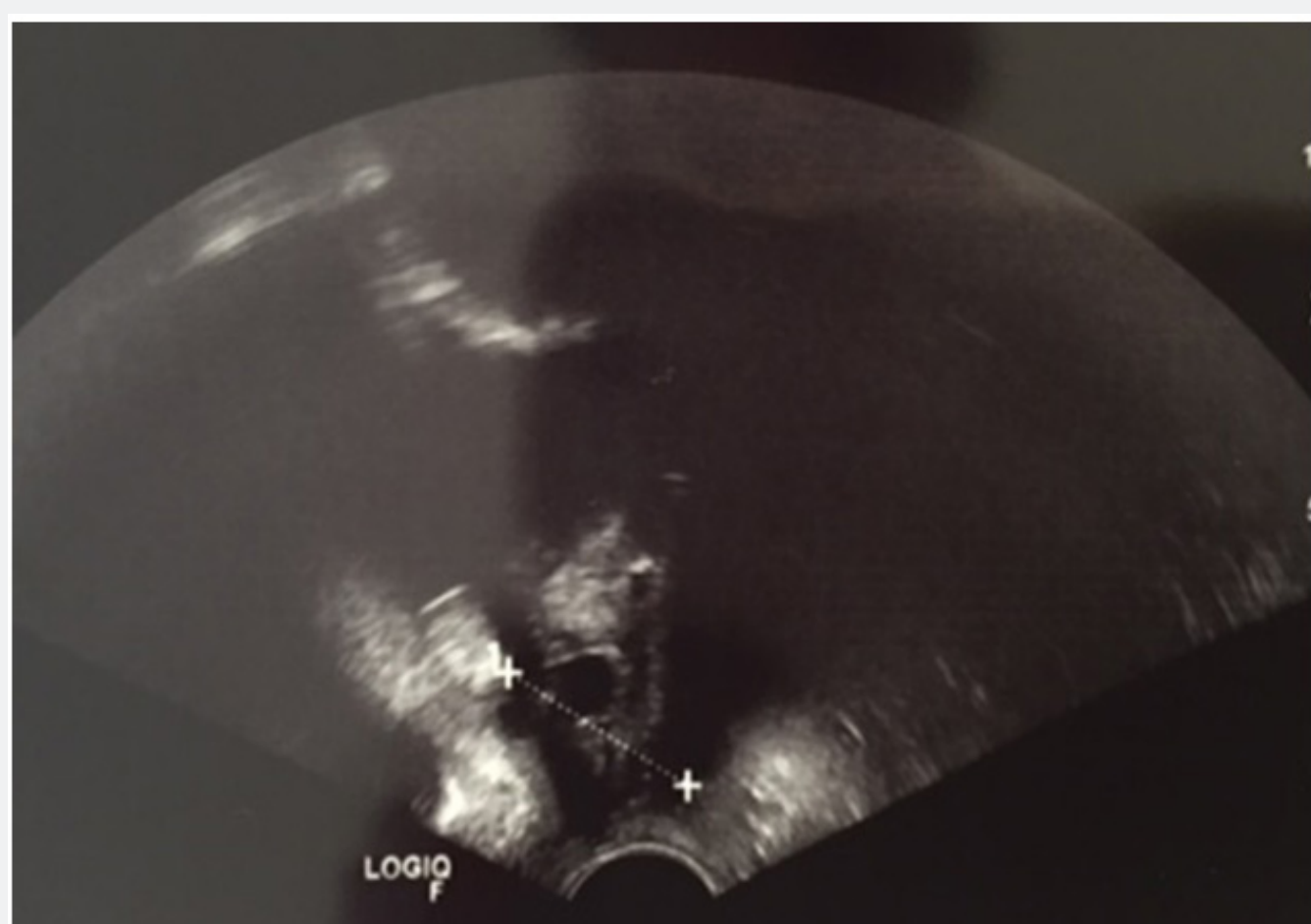

Figure 1: endovaginal ultrasound image of a urethra communicating periurethral diverticulum with a diameter of $3 \mathrm{~cm}$.

\section{Treatment}

Asymptomatic patients can be conservatively treated and followed up. Symptomatic patients should be candidates of surgical treatment. The most common surgical intervention is transvaginal diverticulectomy (83\%), followed by marsupialization of the distal diverticulum (14.9\%-Figure 2), or rarely transabdominal diverticulectomy (1.8\%) [2]. In cases, when due to extensive dissection there is the lack of periurethral fibromuscular tissue provide a cover layer of the excision a Martius fat pad flap can be utilized in urethral reconstruction. Although there is limited available data in the current literature about the efficacy of the surgical modalities, previous studies demonstrated $9.64 \%$ recurrence rate in 5 years period, and a repeat surgery rate of $8.8 \%$, resulting a $23.4 \%$ overall cumulative recurrence rate of UD [2].

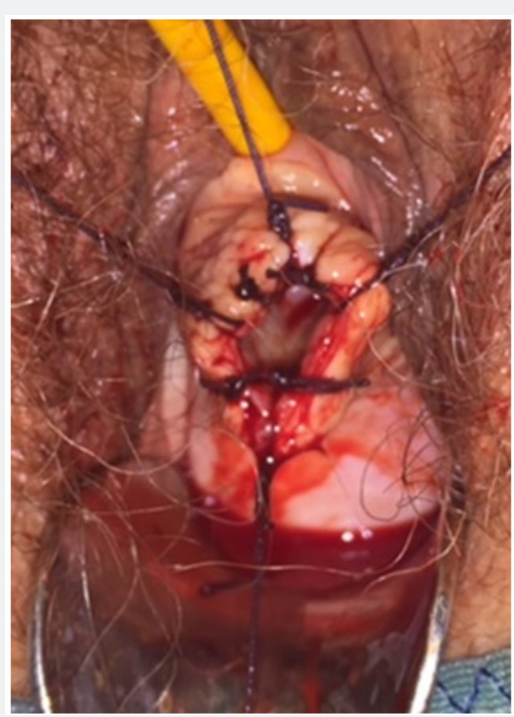

Figure 2: Intraoperative image of a dissected UD after marsupialization. 


\section{Conclusion}

Female UD is rare condition with variable symptoms. Imaging techiques are essential in the augmentation of the physical findings in the diagnosis making. In the symptomatic cases surgical interventions is needed with relatively high recurrence rate.

\section{Acknowledgement}

We would like to express our gratitude to the co-workers, the medical staff and nurses of the Vivantes Humboldt Clinic Pelvic floor and Incontinence Center.

\section{References}

1. Riyach O, Ahsaini A, Tazi MF, Mellas S, Stuurman-Wieringa R, et al (2014) Female urethral diverticulum: cases report and literature. Ann Surg Innov Res 8(1): 1.

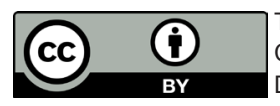

This work is licensed under Creative Commons Attribution 4.0 License

DOI: 10.19080/JGWH.2018.10.555785
2. El-Nashar SA, Bacon MM, Kim-Fine S, Weaver AL, Gebhart JB, et al. (2014) Incidence of female urethral diverticulum: a population-based analysis and literature review. Int Urogynecol J 25(1): 73-79.

3. Menville JG, Mitchell JD (1944) Diverticulum of the female urethra. J Urol 51:411-423.

4. Davis BL, Robinson DG (1970) Diverticula of the female urethra: assay of 120 cases. J Urol 104(6): 850-853.

5. Leach GE, Bavendam TG (1987) Female urethral diverticula. Urology 30(5): 407-415.

6. Routh A (1890) Urethral divert iculum. Br Med J 8: 360-365.

7. Stewart M, Bretland PM, Stidolph NE (1981) Urethral diverticula in the adult female. Br J Urol 53(4): 353-359.

8. Cameron AP (2016) Urethral diverticulum in the female: a metaanalysis of modern series. Minerva Ginecol 68(2): 186-210.

\section{Your next submission with Juniper Publishers will reach you the below assets}

- Quality Editorial service

- Swift Peer Review

- Reprints availability

- E-prints Service

- Manuscript Podcast for convenient understanding

- Global attainment for your research

- Manuscript accessibility in different formats

( Pdf, E-pub, Full Text, Audio)

- Unceasing customer service

Track the below URL for one-step submission https://juniperpublishers.com/online-submission.php 